\title{
Color-Stable Blue Light-Emitting Diodes Enabled by Effective Passivation of Mixed Halide Perovskites
}

\author{
Hongling Yu, Heyong Wang, Tiankai Zhang, Chang Yi, Guanhaojie Zheng, Chunyang Yin, Max Karlsson, \\ Jiajun Qin, Jianpu Wang, Xiao-Ke Liu,* and Feng Gao*
}

Cite This: J. Phys. Chem. Lett. 2021, 12, 6041-6047

Read Online

ACCESS | 崩 Metrics \& More | 回 Article Recommendations

S1 Supporting Information

ABSTRACT: Bandgap tuning through mixing halide anions is one of the most attractive features for metal halide perovskites. However, mixed halide perovskites usually suffer from phase segregation under electrical biases. Herein, we obtain high-performance and color-stable blue perovskite LEDs (PeLEDs) based on mixed bromide/chloride three-dimensional (3D) structures. We demonstrate that the color instability of $\mathrm{CsPb}\left(\mathrm{Br}_{1-x} \mathrm{Cl}_{x}\right)_{3}$ PeLEDs results from surface defects at perovskite grain boundaries. By effective defect passivation, we achieve colorstable blue electroluminescence from $\mathrm{CsPb}\left(\mathrm{Br}_{1-x} \mathrm{Cl}_{x}\right)_{3}$ PeLEDs, with maximum external quantum efficiencies of up to $4.5 \%$ and high luminance of up to $5351 \mathrm{~cd} \mathrm{~m}^{-2}$ in the sky-blue region $(489 \mathrm{~nm})$. Our work provides new insights into the color instability issue of mixed halide perovskites and can spur new development of high-performance and color-stable blue PeLEDs.

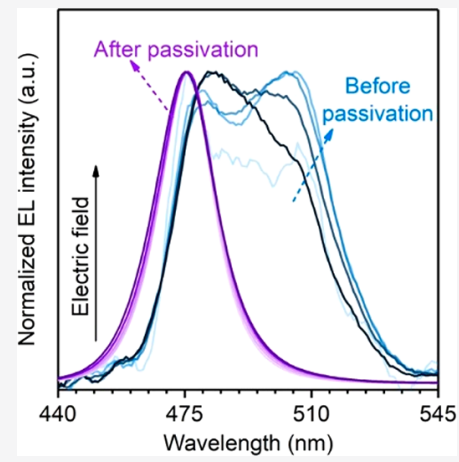

Derovskite light-emitting diodes (PeLEDs) have emerged as 1 a promising candidate for solution-processable display and lighting applications because of their exceptional optical and electrical properties, including high photoluminescence quantum yield (PLQY), narrow emission bandwidth, tunable bandgap, and high charge carrier mobility. ${ }^{1,2}$ In the past several years, considerable progress has been made in this field. ${ }^{3}$ Stateof-the-art green, red, and near-infrared PeLEDs have achieved high external quantum efficiencies (EQEs) over $20 \%{ }^{4-7}$ In spite of these advances, one of the remaining challenges is to develop blue PeLEDs, which show low performance and hence limit practical applications of PeLEDs. ${ }^{8-10}$

One approach for blue PeLEDs is to develop quantumconfined structures based on pure bromide perovskites; for instance, mixed-dimensional perovskites (mixture of $2 \mathrm{D}$ /quasi$2 \mathrm{D} / 3 \mathrm{D}$ phases) and perovskite quantum dots (QDs) have been developed. ${ }^{11-13}$ These quantum-confined structures incorporate long-chain organic ligands to suppress the growth of perovskite crystals, keeping at least one direction of the crystals in the range of their Bohr diameters to increase the bandgap. ${ }^{14-16}$ However, it is rather difficult to realize uniform quantum confinement; for instance, multiple phases exist in mixed-dimensional perovskites, sometimes even leading to broad emission and limiting the color purity. ${ }^{17}$ In addition, these quantum-confined structures often suffer from poor charge injection and hence low luminance of the resulting devices because of the insulating long-chain organic ligands. ${ }^{17-19}$

Another approach to develop blue PeLEDs is to employ mixed $\mathrm{Br} / \mathrm{Cl}$ perovskites. Although continuously tunable emission color with varying halide ions is one of the most appealing features of perovskites, ${ }^{20}$ this mixed halide strategy is often limited by color instability. ${ }^{21,22}$ Most previous reports on mixed $\mathrm{Br} / \mathrm{Cl}$-based blue PeLEDs show continuous color shift under operation, usually ascribed to halogen ion migration. $^{23-26}$ Very recently, we and others have demonstrated that homogenizing the halide composition, by either introducing cationic surfactants in the precursor solution ${ }^{27}$ or vapor-assisted crystallization technique during the film crystallization, ${ }^{10}$ can suppress the spectral shift with largely improved device performance.

Herein, we demonstrate that effective passivation of perovskites can also help to stabilize emission color of mixed halide perovskites. We report color-stable blue PeLEDs with additive incorporation into mixed $\mathrm{Br} / \mathrm{Cl} 3 \mathrm{D}$ perovskites; this additive is found efficient in passivating the surface defects at grain boundaries, which effectively blocks the ion migration channels to eliminate the color instability of $\mathrm{CsPb}\left(\mathrm{Br}_{1-x} \mathrm{Cl}_{x}\right)_{3}$ PeLEDs. The optimized device with sky-blue emission peaking at $489 \mathrm{~nm}$ delivers a peak EQE of $4.5 \%$ and a maximum luminance of $5351 \mathrm{~cd} \mathrm{~m}^{-2}$; these values are $2.9 \%$ and $2240 \mathrm{~cd}$ $\mathrm{m}^{-2}$ for the device with electroluminescence (EL) peaking at $478 \mathrm{~nm}$. As such, our work demonstrates an effective strategy to tackle the color instability issue in mixed halide perovskites

Received: May 14, 2021

Accepted: June 21, 2021

Published: June 24, 2021 
a

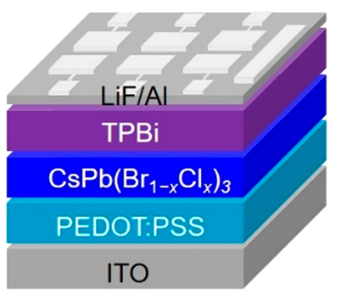

C

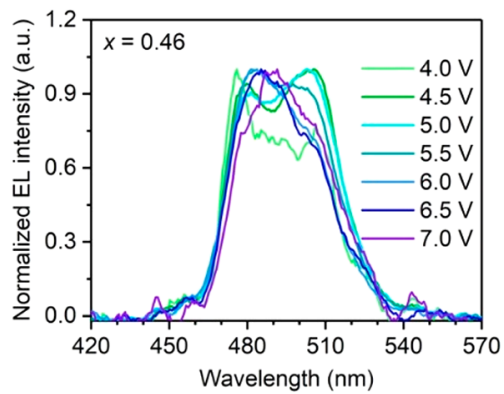

b

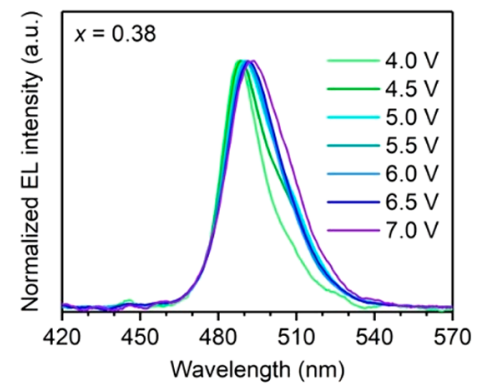

d

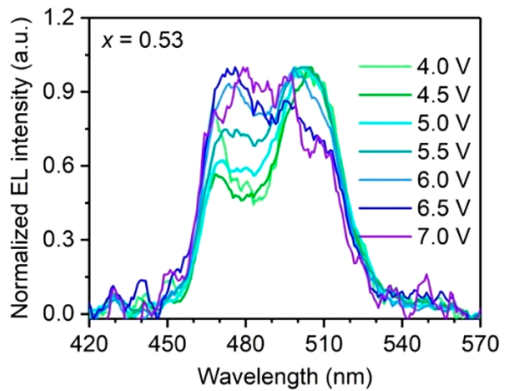

Figure 1. (a) Schematic of the device structure. Normalized EL spectra of devices based on $\mathrm{CsPb}\left(\mathrm{Br}_{1-x} \mathrm{Cl}_{x}\right)_{3}$ perovskite films with (b) $x=0.38$, (c) $x=0.46$, and (d) $x=0.53$.
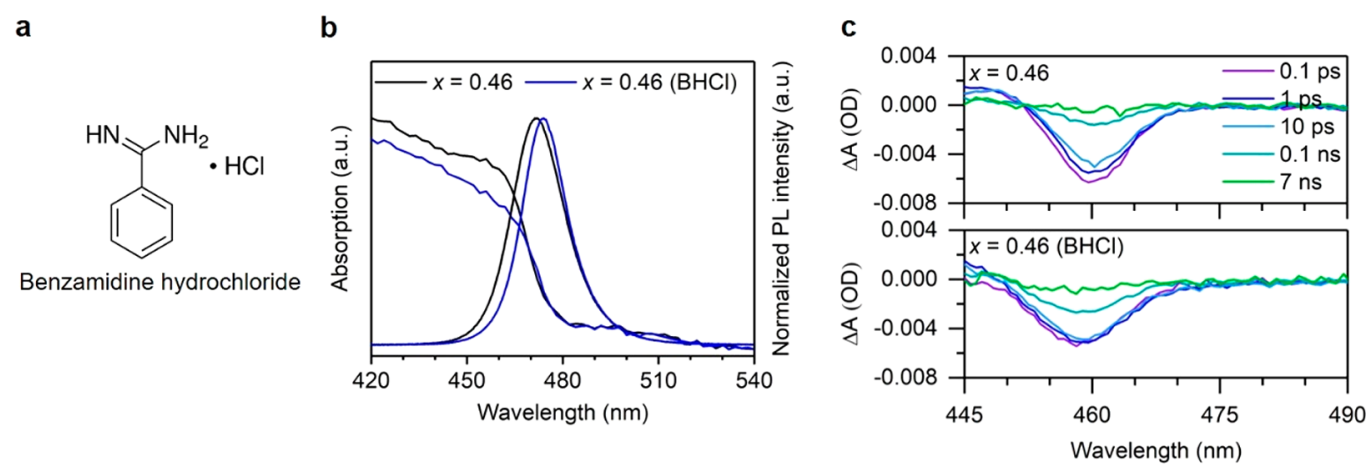

d
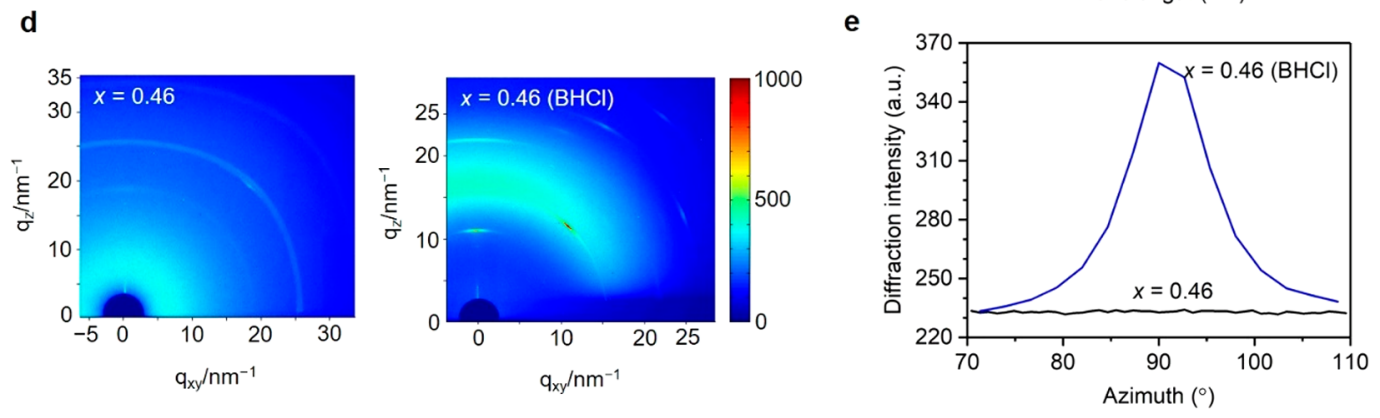

Figure 2. (a) Chemical structure of BHCl. (b) UV-vis absorption and normalized PL spectra ( $\lambda_{\text {ex }}=405 \mathrm{~nm}$ ), (c) TA spectra, (d) GIWAXS patterns, and (e) diffraction intensity of (100) planes versus azimuth angle for control and $\mathrm{BHCl}$-treated $\mathrm{CsPb}\left(\mathrm{Br}_{0.54} \mathrm{Cl} \mathrm{l}_{0.46}\right)_{3}$ perovskite films.

and hopefully can spur new development of high-performance and color-stable blue PeLEDs.

The control samples in this study are made from cesium lead mixed $\mathrm{Br} / \mathrm{Cl}$ perovskites mixed with 4 wt \% poly(ethylene oxide) (PEO) (the role of PEO will be discussed later), described as $\mathrm{CsPb}\left(\mathrm{Br}_{1-x} \mathrm{Cl}_{x}\right)_{3}(x=0.38,0.46$, and 0.53$)$. Perovskite thin films are one-step spin-coated from precursor solutions, followed by thermal annealing at $80{ }^{\circ} \mathrm{C}$ for $40 \mathrm{~min}$ (see Experimental Section in the Supporting Information for details). X-ray diffraction (XRD) measurements are conducted to investigate crystal structures of these films. As shown in Figure S1, the XRD spectra of the perovskite films show diffraction peaks at around $15.4^{\circ}, 21.9^{\circ}$, and $31.2^{\circ}$, which can be assigned to (100), (110), and (200) planes of $\mathrm{CsPb}$ $\left(\mathrm{Br}_{1-x} \mathrm{Cl}_{x}\right)_{3}$, respectively. ${ }^{28}$ The intensities of these diffraction peaks are quite low, indicating poor crystallinities of these films.

We characterize basic photophysical properties of these perovskite films with different $x$ values. The absorption onset (Figure S2) and bandgap energy $E_{\mathrm{g}}$ (Figure S3a-c, determined 
a

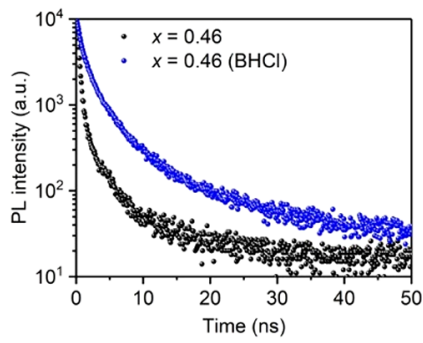

d

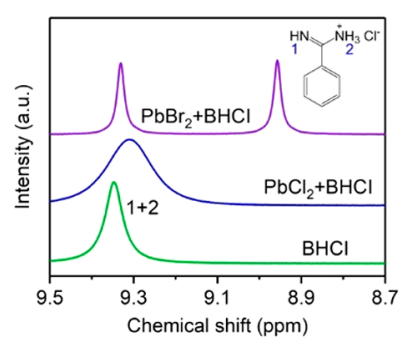

b

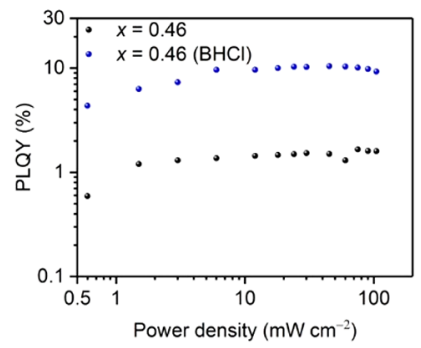

c

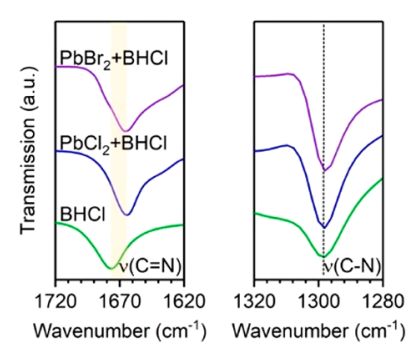

e

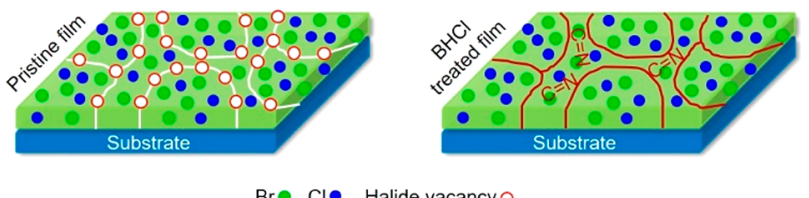

$\mathrm{Br} \bullet \mathrm{Cl} \bullet$ Halide vacancy $\mathrm{O}$

Figure 3. (a) PL decay curves and (b) power-dependent PLQYs of control and BHCl-treated $\mathrm{CsPb}\left(\mathrm{Br}_{0.54} \mathrm{Cl}_{0.46}\right)_{3}$ perovskite films. (c) FTIR spectra

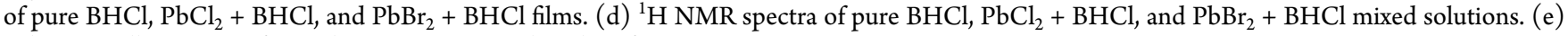
Schematic illustration of $\mathrm{BHCl}$ incorporation induced surface passivation.

by the Tauc plots $\left.{ }^{29}\right)$ of the $\mathrm{CsPb}\left(\mathrm{Br}_{1-x} \mathrm{Cl}_{x}\right)_{3}$ films shift to higher energy with increasing $\mathrm{Cl}$ content. This observation is consistent with the reported bandgap tuning by substituting halide ions. ${ }^{30}$ Similar to the absorption spectra, the PL spectra (Figure S2) of $\mathrm{CsPb}\left(\mathrm{Br}_{1-x} \mathrm{Cl}_{x}\right)_{3}$ films with $x=0.38,0.46$, and 0.53 show continuous blue-shift with peak wavelength of 482 , 471 , and $460 \mathrm{~nm}$, respectively.

We fabricate LEDs based on these $\mathrm{CsPb}\left(\mathrm{Br}_{1-x} \mathrm{Cl}_{x}\right)_{3}$ films by using a device structure of ITO/PEDOT:PSS $(40 \mathrm{~nm}) /$ perovskite $(30 \mathrm{~nm}) / \mathrm{TPBi}(35 \mathrm{~nm}) / \mathrm{LiF}(1 \mathrm{~nm}) / \mathrm{Al}(100 \mathrm{~nm})$ (Figures 1a and S4). The current density-voltage-luminance and EQE characteristics of all the devices are shown in Figure S5a,b, demonstrating low EQEs of less than $0.02 \%$. Figure S5c shows contour maps for the EL spectra for devices with $x=$ $0.38, x=0.46$, and $x=0.53$ over the entire working voltage range. We notice that the EL spectra are weak and broad or even have two peaks under different bias voltages (see the normalized EL spectra in Figure $1 \mathrm{~b}-\mathrm{d}$ ). The additional emission peak might result from multiple emissive species or ion aggregation following ion migration. ${ }^{22,31}$ The poor spectral stability of these control devices also demonstrates that PEO incorporation hardly improves the color stability. Instead, PEO serves to improve film morphology and facilitate charge injection. ${ }^{32,33}$ We compare the LEDs with and without PEO (Figure S6a-c) and find that PEO incorporation remarkably reduces leakage currents in our LEDs and decreases turn-on voltages (Figure S6a), although it has led to very limited improvement in EQE and EL spectral stability (Figure S6b,c).

With the motivation to obtain spectrally stable emission using mixed $\mathrm{Br} / \mathrm{Cl} 3 \mathrm{D}$ perovskite structures, we introduce an additive, organic ammonium chloride salt benzamidine hydrochloride (BHCl; the chemical structure is shown in Figure 2a), into the perovskite precursors to enable the formation of highquality perovskite crystals with suppressed defect states. The BHCl-treated $\mathrm{CsPb}\left(\mathrm{Br}_{1-x} \mathrm{Cl}_{x}\right)_{3} \quad(x=0.38,0.46$, and 0.53$)$ perovskites are termed $x=0.38(\mathrm{BHCl}), x=0.46(\mathrm{BHCl})$, and $x=0.53(\mathrm{BHCl})$ throughout the text, respectively.

We perform spectroscopic characterizations to understand whether the introduction of $\mathrm{BHCl}$ affects the 3D structures of
$\mathrm{CsPb}\left(\mathrm{Br}_{1-x} \mathrm{Cl}_{x}\right)_{3}$ perovskites. In the case of forming lowdimensional phases after $\mathrm{BHCl}$ treatment, we would expect blue shifts in absorption and emission spectra. In contrast, compared to the control films, the BHCl-treated films show almost identical absorption edge, and the PL spectra become narrower with slightly red-shifted peak (Figures $2 b$ and $57 a-$ d), which could be attributed to improved crystalline quality and defect passivation (discussed later). ${ }^{34}$ These absorption and PL spectra suggest that the $\mathrm{BHCl}$-treated films keep the 3D perovskite structures. We provide further evidence based on transient absorption (TA) measurements (Figure 2c). The control and $\mathrm{BHCl}$-treated films show only one single photobleaching peak at 460 and $458 \mathrm{~nm}$, respectively. These results clearly indicate that a single uniform perovskite phase exists in our films and suggest that the additional peaks observed in the pristine films (Figures $1 \mathrm{~b}-\mathrm{d}$ and S5c) result from ion migration and aggregation during the EL measurements. ${ }^{22}$ Ion migration is usually associated with defects in perovskites, especially on the crystal boundaries. ${ }^{35}$

An obvious impact of the $\mathrm{BHCl}$ on the perovskite, as we can determine from structural characterisations, is that $\mathrm{BHCl}$ helps to significantly enhance crystallization of perovskites. XRD results (Figure S8) show that the intensities of the dominant peaks have largely increased by incorporating $\mathrm{BHCl}$, suggesting an enhancement of the crystallinity or formation of textures in the BHCl-treated films compared to the control films (Figure S1). In addition, the XRD results (Figure S8) show diffraction peaks only from 3D structures, further confirming the absence of low-dimensional phases. ${ }^{36}$

We further conduct grazing incidence wide angle X-ray scattering (GIWAXS) measurements to understand the effect of $\mathrm{BHCl}$ on the perovskite crystallization. As shown in Figure $2 \mathrm{~d}$, the diffraction pattern in the control film is nearly diffraction rings, and the intensity along the azimuth angle of each diffraction rings shows only slight fluctuations. After $\mathrm{BHCl}$ incorporation, an obvious enhancement of diffraction intensity occurs as indicated by the bright yellow/red spots; the diffraction signals located at $q=10.7,15.5$, and $21.3 \mathrm{~nm}^{-1}$ are assigned to (100), (110), and (200) crystal planes. ${ }^{10}$ In 


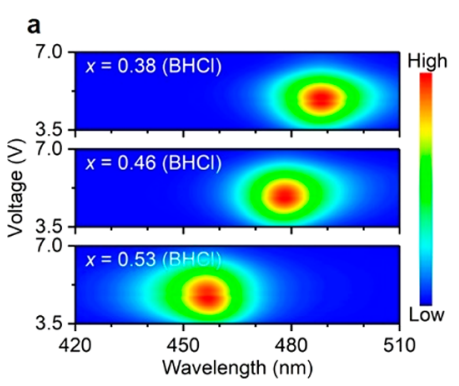

d

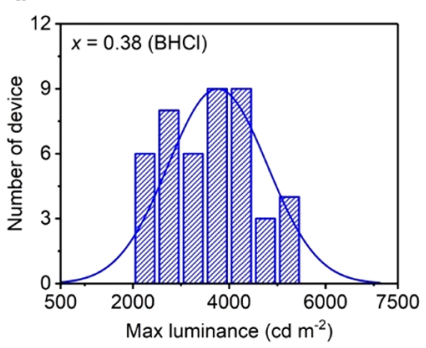

b

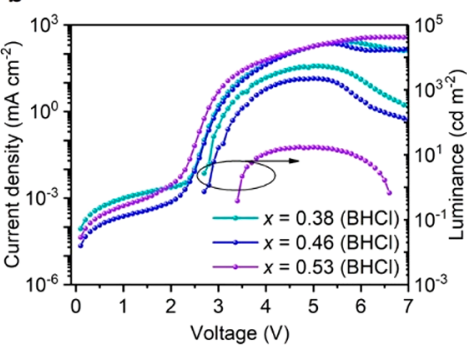

e

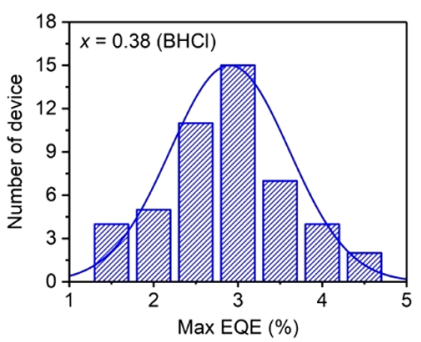

c

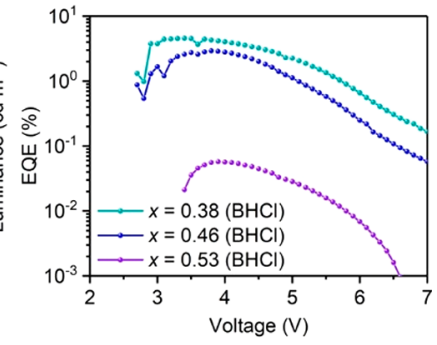

f

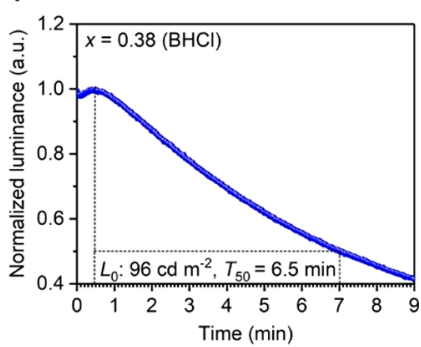

Figure 4. (a) Contour plots of voltage-dependent EL spectra across the entire working range and (b) current density-voltage-luminance and (c) EQE-voltage curves of devices based on BHCl-treated $\mathrm{CsPb}\left(\mathrm{Br}_{1-x} \mathrm{Cl}_{x}\right)_{3}$ perovskite films. Histograms of maximum (d) luminance and (e) EQE for $x=0.38(\mathrm{BHCl})$-based devices. (f) Operating lifetime of $x=0.38(\mathrm{BHCl})$-based device under a constant current density of $5 \mathrm{~mA} \mathrm{~cm}^{-2}$.

addition, the diffraction intensity at different azimuth angles presents a preferred orientation along the vertical direction. To analyze the evolution of microstructural arrangement, we study the variation of diffraction intensity of the perovskite (100) plane along the vertical direction. As depicted in Figure $2 \mathrm{e}$, the diffraction intensity at the azimuth angle of around $90^{\circ}$ increases obviously in the $\mathrm{BHCl}$-treated film. Considering the geometric structure of (100), we ensure that $\mathrm{BHCl}$ promotes microstructural arrangements along the out-of-plane direction which finally results in high crystallinity with long-range order. The scanning electron microscopy (SEM) results (Figure $\mathrm{S} 9 \mathrm{a}-\mathrm{f}$ ) also show that the $\mathrm{BHCl}$-treated perovskite grains grow differently from those of the control films.

In addition to enhanced crystallinity, the incorporation of $\mathrm{BHCl}$ helps to reduce defect densities, as evidenced by timeresolved PL and power-dependent PLQY measurements. Compared with the control film, the BHCl-treated sample shows longer PL lifetime (Figure 3a); in addition, the $\mathrm{BHCl}$ treated sample shows enhanced PLQYs across a wide range of power density, with a peak PLQY of $10.4 \%$ (Figure $3 \mathrm{~b}$ ). These results indicate that $\mathrm{BHCl}$ incorporation leads to reduced defect densities, which can result from enhanced crystallization and effective defect passivation. Because the incorporation of $\mathrm{BHCl}$ maintains the $3 \mathrm{D}$ structures of $\mathrm{CsPb}\left(\mathrm{Br}_{1-x} \mathrm{Cl}_{x}\right)_{3}$, the passivation is supposed to be at the crystal boundaries of these perovskites. $^{37}$

In order to understand how $\mathrm{BHCl}$ passivates the defects, we perform Fourier-transform infrared (FTIR) measurements (Figure 3c). The $\mathrm{C}=\mathrm{N}$ stretching $\left(\nu(\mathrm{C}=\mathrm{N}), 1676 \mathrm{~cm}^{-1}\right)^{38,39}$ of the $\mathrm{BHCl}$ unit shifts to lower wavenumbers in the $\mathrm{PbCl}_{2}+$ $\mathrm{BHCl}$ and $\mathrm{PbBr}_{2}+\mathrm{BHCl}$ mixed films. However, $\mathrm{C}-\mathrm{N}$ stretching $\left(\nu(\mathrm{C}-\mathrm{N}), 1298 \mathrm{~cm}^{-1}\right)^{40}$ remains unchanged with respect to that of pure $\mathrm{BHCl}$. These results indicate that the $\mathrm{C}=\mathrm{N}$ group in $\mathrm{BHCl}$ can interact with uncoordinated $\mathrm{Pb}$ atoms of $\mathrm{PbX}_{2}$. This interaction is further confirmed by ${ }^{1} \mathrm{H}$ nuclear magnetic resonance $\left({ }^{1} \mathrm{H}\right.$ NMR) measurements (Figure $3 \mathrm{~d}$ ). Compared to pure $\mathrm{BHCl}$ solution, the resonance signal of $\delta=$ $9.35 \mathrm{ppm}\left(\mathrm{H}^{(1+2)}\right)$ undergoes a significant broadening or even splitting in $\mathrm{PbCl}_{2}+\mathrm{BHCl}$ and $\mathrm{PbBr}_{2}+\mathrm{BHCl}$ mixed solutions, respectively. Hence, the interaction between $\mathrm{BHCl}$ and uncoordinated $\mathrm{Pb}$ contributes to surface passivation of the perovskites. $^{41,42}$

We propose a model to interpret the differences in crystal grains of control and $\mathrm{BHCl}$-treated films (Figure 3e). In spincoated $\mathrm{CsPb}\left(\mathrm{Br}_{1-x} \mathrm{Cl}_{x}\right)_{3}$ perovskite films, a large number of surface defects, including halide vacancies, exist at grain boundaries, which could provide pathways for halide ion migration and result in low-energy emissions. ${ }^{35,43,44}$ After $\mathrm{BHCl}$ incorporation, the perovskite crystals are preferentially oriented with reduced defect density. More importantly, $\mathrm{BHCl}$ could create surface-passivated grains, suppressing the ion migration channels.

Encouraged by efficient passivation and enhanced crystallization enabled by $\mathrm{BHCl}$ incorporation, we are motivated to move forward to fabricate color-stable blue PeLEDs based on $\mathrm{BHCl}$-treated $\mathrm{CsPb}\left(\mathrm{Br}_{1-x} \mathrm{Cl}_{x}\right)_{3}$. The contour maps in Figure $4 \mathrm{a}$ and normalized EL spectra in Figure $\mathrm{S} 10 \mathrm{a}-\mathrm{c}$ clearly indicate excellent EL spectral stability of the devices. As further indicated in Table S1, the devices show almost constant Commission Internationale de l'Eclairage (CIE) coordinates with increasing voltage. In addition, $\mathrm{BHCl}$ incorporation, particularly for the films with $x=0.38$ and 0.46 , suppresses LED leakage currents and results in higher luminance and efficiency (Figures $4 \mathrm{~b}, \mathrm{c}$ and S5a,b). Thus, in addition to enhanced crystallinity and defect passivation, $\mathrm{BHCl}$ incorporation may also act as a thin insulating layer together with PEO, suppressing electrical shunts that could have occurred in LEDs with discontinuous perovskite films. ${ }^{6}$ As such, the control device with $x=0.38$ demonstrates low EQE of less than $0.02 \%$ and luminance of less than $60 \mathrm{~cd} \mathrm{~m}^{-2}$; with $\mathrm{BHCl}$ incorporation, the device with $x=0.38(\mathrm{BHCl})$ exhibits a peak EQE of $4.5 \%$ and high luminance of $5351 \mathrm{~cd} \mathrm{~m}^{-2}$. Statistical histograms of maximum luminance and EQE of the devices collected from 48 devices (Figure 4d,e) illustrate good reproducibility of our devices.

Figure 4f shows the operational stability of an $x=0.38$ ( $\mathrm{BHCl}$ )-based LED, measured at a constant current density of $5 \mathrm{~mA} \mathrm{~cm}{ }^{-2}$ with an initial luminance of $96 \mathrm{~cd} \mathrm{~m}^{-2}$. The 
luminance value decays to $50 \%$ of its initial value $\left(T_{50}\right)$ after $6.5 \mathrm{~min}$. Most importantly, the device shows excellent color stability under operation; the peak wavelengths of EL spectra remain identical during the device stability test (Figure S11). The BHCl-treated films also exhibit excellent spectral stability upon continuous light illumination; after $1 \mathrm{~h}$ illumination of $405 \mathrm{~nm}$ laser light, no PL shift is observed in these films except for a decrease of the PL intensity (Figure S12a-c).

In conclusion, we have found that the color instability issues in $\mathrm{CsPb}\left(\mathrm{Br}_{1-x} \mathrm{Cl}_{x}\right)_{3}$ 3D structures appear in the form of additional low-energy emissions, which are related to surface defects at grain boundaries. We prove that such detrimental emissions can be effectively eliminated by passivation through incorporating passivating agents into the precursors. By incorporating $\mathrm{BHCl}$ as an additive that can modulate the crystallization process of the perovskite grains and generate surface-passivated grain boundaries, we present color-stable $\mathrm{CsPb}\left(\mathrm{Br}_{1-x} \mathrm{Cl}_{x}\right)_{3}$ PeLEDs with maximum EQEs of up to $4.5 \%$ and high luminance of up to $5351 \mathrm{~cd} \mathrm{~m}^{-2}$ in the sky-blue region $(489 \mathrm{~nm})$. Our work provides new insights into the color stability of mixed halide perovskites and sheds light on the development of high-performance and color-stable blue PeLEDs based on $\mathrm{CsPb}\left(\mathrm{Br}_{1-x} \mathrm{Cl}_{x}\right)_{3}$ 3D structures.

\section{ASSOCIATED CONTENT}

\section{(5) Supporting Information}

The Supporting Information is available free of charge at https://pubs.acs.org/doi/10.1021/acs.jpclett.1c01547.

Detailed experimental methods, XRD patterns, absorption spectra, PL spectra, SEM images, and EL results (PDF)

\section{AUTHOR INFORMATION}

\section{Corresponding Authors}

Xiao-Ke Liu - Department of Physics, Chemistry and Biology (IFM), Linköping University, Linköping 58183, Sweden; 이이.org/0000-0001-5661-8174; Email: xiaoke.liu@ liu.se

Feng Gao - Department of Physics, Chemistry and Biology (IFM), Linköping University, Linköping 58183, Sweden; ๑ orcid.org/0000-0002-2582-1740; Email: feng.gao@ liu.se

\section{Authors}

Hongling Yu - Department of Physics, Chemistry and Biology (IFM), Linköping University, Linköping 58183, Sweden

Heyong Wang - Department of Physics, Chemistry and Biology (IFM), Linköping University, Linköping 58183, Sweden

Tiankai Zhang - Department of Physics, Chemistry and Biology (IFM), Linköping University, Linköping 58183, Sweden

Chang Yi - Key Laboratory of Flexible Electronics (KLOFE) \& Institute of Advanced Materials (IAM), Jiangsu National Synergetic Innovation Center for Advanced Materials (SICAM), Nanjing Tech University, Nanjing 211816, China

Guanhaojie Zheng - Department of Physics, Chemistry and Biology (IFM), Linköping University, Linköping 58183, Sweden

Chunyang Yin - Department of Physics, Chemistry and Biology (IFM), Linköping University, Linköping 58183, Sweden
Max Karlsson - Department of Physics, Chemistry and Biology (IFM), Linköping University, Linköping 58183, Sweden

Jiajun Qin - Department of Physics, Chemistry and Biology (IFM), Linköping University, Linköping 58183, Sweden;

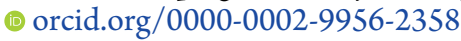

Jianpu Wang - Key Laboratory of Flexible Electronics (KLOFE) \& Institute of Advanced Materials (IAM), Jiangsu National Synergetic Innovation Center for Advanced Materials (SICAM), Nanjing Tech University, Nanjing 211816, China; 이이이.org/0000-0002-2158-8689

Complete contact information is available at:

https://pubs.acs.org/10.1021/acs.jpclett.1c01547

\section{Notes}

The authors declare no competing financial interest.

\section{ACKNOWLEDGMENTS}

This work was supported by the ERC Starting Grant (No. 717026), the Swedish Energy Agency Energimyndigheten (Nos. 48758-1 and 44651-1), the Swedish Foundation for International Cooperation in Research and Higher Education (No. CH2018-7736), and the Swedish Government Strategic Research Area in Materials Science on Functional Materials at Linköping University (Faculty Grant SFO-Mat-LiU No. 200900971). H.Y. and H.W. acknowledge the financial support of the China Scholarship Council. We thank L. Zhu and J. Wang for insightful discussions and thank T. Pullerits for facilitating TA measurements. We also thank BL14B1 in Shanghai Synchrotron Radiation Facility for providing the beam time.

\section{REFERENCES}

(1) Sutherland, B. R.; Sargent, E. H. Perovskite Photonic Sources. Nat. Photonics 2016, 10, 295-302.

(2) Quan, L. N.; Rand, B. P.; Friend, R. H.; Mhaisalkar, S. G.; Lee, T.-W.; Sargent, E. H. Perovskites for Next-Generation Optical Sources. Chem. Rev. 2019, 119, 7444-7477.

(3) Liu, X.-K.; Xu, W.; Bai, S.; Jin, Y.; Wang, J.; Friend, R. H.; Gao, F. Metal Halide Perovskites for Light-Emitting Diodes. Nat. Mater. 2021, 20, 10-21.

(4) Lin, K.; Xing, J.; Quan, L. N.; de Arquer, F. P. G.; Gong, X.; Lu, J.; Xie, L.; Zhao, W.; Zhang, D.; Yan, C.; et al. Perovskite LightEmitting Diodes with External Quantum Efficiency Exceeding 20 per Cent. Nature 2018, 562, 245-248.

(5) Chiba, T.; Hayashi, Y.; Ebe, H.; Hoshi, K.; Sato, J.; Sato, S.; Pu, Y.-J.; Ohisa, S.; Kido, J. Anion-Exchange Red Perovskite Quantum Dots with Ammonium Iodine Salts for Highly Efficient Light-Emitting Devices. Nat. Photonics 2018, 12, 681-687.

(6) Cao, Y.; Wang, N.; Tian, H.; Guo, J.; Wei, Y.; Chen, H.; Miao, Y.; Zou, W.; Pan, K.; He, Y.; et al. Perovskite Light-Emitting Diodes Based on Spontaneously Formed Submicrometre-Scale Structures. Nature 2018, 562, 249-253.

(7) Xu, W.; Hu, Q.; Bai, S.; Bao, C.; Miao, Y.; Yuan, Z.; Borzda, T.; Barker, A. J.; Tyukalova, E.; Hu, Z.; et al. Rational Molecular Passivation for High-Performance Perovskite Light-Emitting Diodes. Nat. Photonics 2019, 13, 418-424.

(8) Kumawat, N. K.; Liu, X.-K.; Kabra, D.; Gao, F. Blue Perovskite Light-Emitting Diodes: Progress, Challenges and Future Directions. Nanoscale 2019, 11, 2109-2120.

(9) Fang, T.; Zhang, F.; Yuan, S.; Zeng, H.; Song, J. Recent Advances and Prospects toward Blue Perovskite Materials and LightEmitting Diodes. InfoMat 2019, 1, 211-233.

(10) Karlsson, M.; Yi, Z.; Reichert, S.; Luo, X.; Lin, W.; Zhang, Z.; Bao, C.; Zhang, R.; Bai, S.; Zheng, G.; et al. Mixed Halide Perovskites 
for Spectrally Stable and High-Efficiency Blue Light-Emitting Diodes. Nat. Commun. 2021, 12, 361.

(11) Kumar, S.; Jagielski, J.; Yakunin, S.; Rice, P.; Chiu, Y.-C.; Wang, M.; Nedelcu, G.; Kim, Y.; Lin, S.; Santos, E. J. G.; et al. Efficient Blue Electroluminescence Using Quantum-Confined Two-Dimensional Perovskites. ACS Nano 2016, 10, 9720-9729.

(12) Xing, J.; Zhao, Y.; Askerka, M.; Quan, L. N.; Gong, X.; Zhao, W.; Zhao, J.; Tan, H.; Long, G.; Gao, L.; et al. Color-Stable Highly Luminescent Sky-Blue Perovskite Light-Emitting Diodes. Nat. Commun. 2018, 9, 3541.

(13) Wang, S.; Bi, C.; Yuan, J.; Zhang, L.; Tian, J. Original CoreShell Structure of Cubic $\mathrm{CsPbBr}_{3}$ @Amorphous $\mathrm{CsPbBr}_{x}$ Perovskite Quantum Dots with a High Blue Photoluminescence Quantum Yield of over 80\%. ACS Energy Lett. 2018, 3, 245-251.

(14) Pan, A.; He, B.; Fan, X.; Liu, Z.; Urban, J. J.; Alivisatos, A. P.; He, L.; Liu, Y. Insight into the Ligand-Mediated Synthesis of Colloidal $\mathrm{CsPbBr}_{3}$ Perovskite Nanocrystals: The Role of Organic Acid, Base, and Cesium Precursors. ACS Nano 2016, 10, 7943-7954.

(15) Dirin, D. N.; Protesescu, L.; Trummer, D.; Kochetygov, I. V.; Yakunin, S.; Krumeich, F.; Stadie, N. P.; Kovalenko, M. V. Harnessing Defect-Tolerance at the Nanoscale: Highly Luminescent Lead Halide Perovskite Nanocrystals in Mesoporous Silica Matrixes. Nano Lett. 2016, 16, 5866-5874.

(16) Yu, H.; Wang, H.; Zhang, J.; Lu, J.; Yuan, Z.; Xu, W.; Hultman, L.; Bakulin, A. A.; Friend, R. H.; Wang, J.; et al. Efficient and Tunable Electroluminescence from In Situ Synthesized Perovskite Quantum Dots. Small 2019, 15, 1804947.

(17) Chen, Z.; Zhang, C.; Jiang, X.-F.; Liu, M.; Xia, R.; Shi, T.; Chen, D.; Xue, Q.; Zhao, Y.-J.; Su, S.; et al. High-Performance ColorTunable Perovskite Light Emitting Devices through Structural Modulation from Bulk to Layered Film. Adv. Mater. 2017, 29, 1603157.

(18) Jiang, Y.; Qin, C.; Cui, M.; He, T.; Liu, K.; Huang, Y.; Luo, M.; Zhang, L.; Xu, H.; Li, S.; et al. Spectra Stable Blue Perovskite LightEmitting Diodes. Nat. Commun. 2019, 10, 1868.

(19) Liu, Y.; Cui, J.; Du, K.; Tian, H.; He, Z.; Zhou, Q.; Yang, Z.; Deng, Y.; Chen, D.; Zuo, X.; et al. Efficient Blue Light-Emitting Diodes Based on Quantum-Confined Bromide Perovskite Nanostructures. Nat. Photonics 2019, 13, 760-764.

(20) Protesescu, L.; Yakunin, S.; Bodnarchuk, M. I.; Krieg, F.; Caputo, R.; Hendon, C. H.; Yang, R. X.; Walsh, A.; Kovalenko, M. V. Nanocrystals of Cesium Lead Halide Perovskites $\left(\mathrm{CsPbX}_{3}, \mathrm{X}=\mathrm{Cl}, \mathrm{Br}\right.$, and I): Novel Optoelectronic Materials Showing Bright Emission with Wide Color Gamut. Nano Lett. 2015, 15, 3692-3696.

(21) Hoke, E. T.; Slotcavage, D. J.; Dohner, E. R.; Bowring, A. R.; Karunadasa, H. I.; McGehee, M. D. Reversible Photo-Induced Trap Formation in Mixed-Halide Hybrid Perovskites for Photovoltaics. Chem. Sci. 2015, 6, 613-617.

(22) Vashishtha, P.; Halpert, J. E. Field-Driven Ion Migration and Color Instability in Red-Emitting Mixed Halide Perovskite Nanocrystal Light-Emitting Diodes. Chem. Mater. 2017, 29, 5965-5973.

(23) Li, G.; Rivarola, F. W. R.; Davis, N. J. L. K.; Bai, S.; Jellicoe, T. C.; de la Peña, F.; Hou, S.; Ducati, C.; Gao, F.; Friend, R. H.; et al. Highly Efficient Perovskite Nanocrystal Light-Emitting Diodes Enabled by a Universal Crosslinking Method. Adv. Mater. 2016, 28, 3528-3534.

(24) Vashishtha, P.; Ng, M.; Shivarudraiah, S. B.; Halpert, J. E. High Efficiency Blue and Green Light-Emitting Diodes Using RuddlesdenPopper Inorganic Mixed Halide Perovskites with Butylammonium Interlayers. Chem. Mater. 2019, 31, 83-89.

(25) Li, Z.; Chen, Z.; Yang, Y.; Xue, Q.; Yip, H.-L.; Cao, Y. Modulation of Recombination Zone Position for Quasi-TwoDimensional Blue Perovskite Light-Emitting Diodes with Efficiency Exceeding 5\%. Nat. Commun. 2019, 10, 1027.

(26) Wang, K.-H.; Peng, Y.; Ge, J.; Jiang, S.; Zhu, B.-S.; Yao, J.-S.; Yin, Y.-C.; Yang, J.-N.; Zhang, Q.; Yao, H.-B. Efficient and ColorTunable Quasi-2D CsPbBr${ }_{x} \mathrm{Cl}_{3-x}$ Perovskite Blue Light-Emitting Diodes. ACS Photonics 2019, 6, 667-676.
(27) Cheng, L.; Yi, C.; Tong, Y.; Zhu, L.; Kusch, G.; Wang, X.; Wang, X.; Jiang, T.; Zhang, H.; Zhang, J. Halide Homogenization for High-Performance Blue Perovskite Electroluminescence. Research 2020, 2020, 9017871.

(28) Li, Z.; Kong, L.; Huang, S.; Li, L. Highly Luminescent and Ultrastable $\mathrm{CsPbr}_{3}$ Perovskite Quantum Dots Incorporated into a Silica/Alumina Monolith. Angew. Chem., Int. Ed. 2017, 56, 81348138.

(29) Eperon, G. E.; Stranks, S. D.; Menelaou, C.; Johnston, M. B.; Herz, L. M.; Snaith, H. J. Formamidinium Lead Trihalide: A Broadly Tunable Perovskite for Efficient Planar Heterojunction Solar Cells. Energy Environ. Sci. 2014, 7, 982-988.

(30) Kumawat, N. K.; Dey, A.; Kumar, A.; Gopinathan, S. P.; Narasimhan, K. L.; Kabra, D. Band Gap Tuning of $\mathrm{CH}_{3} \mathrm{NH}_{3} \mathrm{~Pb}$ $\left(\mathrm{Br}_{1-x} \mathrm{Cl}_{x}\right)_{3}$ Hybrid Perovskite for Blue Electroluminescence. ACS Appl. Mater. Interfaces 2015, 7, 13119-13124.

(31) Yang, X.; Zhang, X.; Deng, J.; Chu, Z.; Jiang, Q.; Meng, J.; Wang, P.; Zhang, L.; Yin, Z.; You, J. Efficient Green Light-Emitting Diodes Based on Quasi-Two-Dimensional Composition and Phase Engineered Perovskite with Surface Passivation. Nat. Commun. 2018, 9, 570 .

(32) Ling, Y.; Tian, Y.; Wang, X.; Wang, J. C.; Knox, J. M.; PerezOrive, F.; Du, Y.; Tan, L.; Hanson, K.; Ma, B.; et al. Enhanced Optical and Electrical Properties of Polymer-Assisted All-Inorganic Perovskites for Light-Emitting Diodes. Adv. Mater. 2016, 28, 8983-8989.

(33) Wu, C.; Zou, Y.; Wu, T.; Ban, M.; Pecunia, V.; Han, Y.; Liu, Q.; Song, T.; Duhm, S.; Sun, B. Improved Performance and Stability of All-Inorganic Perovskite Light-Emitting Diodes by Antisolvent Vapor Treatment. Adv. Funct. Mater. 2017, 27, 1700338.

(34) Fei, C.; Li, B.; Zhang, R.; Fu, H.; Tian, J.; Cao, G. Highly Efficient and Stable Perovskite Solar Cells Based on Monolithically Grained $\mathrm{CH}_{3} \mathrm{NH}_{3} \mathrm{PbI}_{3}$ Film. Adv. Energy Mater. 2017, 7, 1602017.

(35) Shao, Y.; Fang, Y.; Li, T.; Wang, Q.; Dong, Q.; Deng, Y.; Yuan, Y.; Wei, H.; Wang, M.; Gruverman, A.; et al. Grain Boundary Dominated Ion Migration in Polycrystalline Organic-Inorganic Halide Perovskite Films. Energy Environ. Sci. 2016, 9, 1752-1759.

(36) Shang, Y.; Li, G.; Liu, W.; Ning, Z. Quasi-2D Inorganic $\mathrm{CsPbBr}_{3}$ Perovskite for Efficient and Stable Light-Emitting Diodes. Adv. Funct. Mater. 2018, 28, 1801193.

(37) Li, X.; Ibrahim Dar, M.; Yi, C.; Luo, J.; Tschumi, M.; Zakeeruddin, S. M.; Nazeeruddin, M. K.; Han, H.; Grätzel, M. Improved Performance and Stability of Perovskite Solar Cells by Crystal Crosslinking with Alkylphosphonic Acid $\omega$-Ammonium Chlorides. Nat. Chem. 2015, 7, 703-711.

(38) Wang, H.; Kosasih, F. U.; Yu, H.; Zheng, G.; Zhang, J.; Pozina, G.; Liu, Y.; Bao, C.; Hu, Z.; Liu, X.; et al. Perovskite-Molecule Composite Thin Films for Efficient and Stable Light-Emitting Diodes. Nat. Commun. 2020, 11, 891.

(39) Dou, B.; Wheeler, L. M.; Christians, J. A.; Moore, D. T.; Harvey, S. P.; Berry, J. J.; Barnes, F. S.; Shaheen, S. E.; van Hest, M. F. A. M. Degradation of Highly Alloyed Metal Halide Perovskite Precursor Inks: Mechanism and Storage Solutions. ACS Energy Lett. 2018, 3, 979-985.

(40) Rahul; Singh, P. K.; Singh, R.; Singh, V.; Bhattacharya, B.; Khan, Z. H. New Class of Lead Free Perovskite Material for Low-Cost Solar Cell Application. Mater. Res. Bull. 2018, 97, 572-577.

(41) Bi, D.; Li, X.; Milić, J. V.; Kubicki, D. J.; Pellet, N.; Luo, J.; LaGrange, T.; Mettraux, P.; Emsley, L.; Zakeeruddin, S. M.; et al. Multifunctional Molecular Modulators for Perovskite Solar Cells with over 20\% Efficiency and High Operational Stability. Nat. Commun. 2018, 9, 4482.

(42) Peng, J.; Khan, J. I.; Liu, W.; Ugur, E.; Duong, T.; Wu, Y.; Shen, H.; Wang, K.; Dang, H.; Aydin, E.; et al. A Universal Double-Side Passivation for High Open-Circuit Voltage in Perovskite Solar Cells: Role of Carbonyl Groups in Poly(Methyl Methacrylate). Adv. Energy Mater. 2018, 8, 1801208.

(43) deQuilettes, D. W.; Zhang, W.; Burlakov, V. M.; Graham, D. J.; Leijtens, T.; Osherov, A.; Bulović, V.; Snaith, H. J.; Ginger, D. S.; 
Stranks, S. D. Photo-Induced Halide Redistribution in OrganicInorganic Perovskite Films. Nat. Commun. 2016, 7, 11683.

(44) Eames, C.; Frost, J. M.; Barnes, P. R. F.; O’Regan, B. C.; Walsh, A.; Islam, M. S. Ionic Transport in Hybrid Lead Iodide Perovskite Solar Cells. Nat. Commun. 2015, 6, 7497. 